\title{
Gradient Morphophonology: Evidence from Uyghur Vowel Harmony
}

\author{
Adam G. McCollum \\ University of California San Diego
}

\section{Introduction}

In Structuralist and early Generative work, all grammatical knowledge was assumed to be categorical and discrete (e.g. (Bloomfield 1933; Chomsky \& Halle 1968). As a result, phonetics, being inherently gradient, was regarded as extra-grammatical (de Saussure 1993). While such a view of phonetics was still espoused by Chomsky \& Halle (1968), a contemporary body of phonetic literature discovered that phonetic patterns are language-specific and must form part of a speaker's knowledge of their language (Öhman 1966; Keating 1985). Such findings suggest that all grammatical knowledge is not, by definition, categorical. In much of current linguistic theory, gradience plays a role in phonetics and pragmatics, but has little import for other modules of the grammar.

Irrespective of its ontological status, the prevailing assumption is that phonological knowledge is categorical. Consequently, gradience is typically used to differentiate phonetic from phonological patterns, in effect, further entrenching the assumed categoricality of phonology (e.g. Cohn 1993, 2006; Zsiga 1997). To be clear, gradience is not synonymous with optionality. I use the term gradience to refer to degrees of phonetic effect rather than frequency of effects. The commonly held view is that phonological patterns involve substitution of abstract symbols, producing outputs that are indistinguishable from their nonderived counterparts. In contrast, phonetics is concerned with the translation of phonological abstractions into continuous space and time. Gradience as the primary diagnostic of phonetic versus phonological status has encountered one recurrent challenge, incomplete neutralization. In many cases, putatively phonological patterns, like word-final devoicing, have been shown to exhibit subphonemic gradience. In other words, these patterns produce sounds that are not acoustically or articulatorily identical to their non-derived counterparts (e.g. Port \& O'Dell 1985; Warner et al. 2004; Ernestus 2011; Braver 2013). One interesting generalization concerning attested cases of gradience is that they have all, at some time or another, been analyzed as post-lexical. Within Lexical Phonology (Mohanan 1982; Kiparsky 1985), the core of phonology is categorical and structure-preserving. Post-lexical phonology, on the other hand, may be gradient, producing sounds not present in the underlying inventory. Thus, in the traditional generative view, gradience is confined to phonetics, or in Lexical Phonology, phonetics and post-lexical phonology. Under both views, though, the categoricality of morphophonology is preserved. If all attested cases of subphonemic gradience are either post-lexical or phonetic, the question is thus, may morphophonological patterns be gradient? To-date, the answer is no. Cohn (2006:36) states the issue thusly:

Morphophonemic alternations are at the very core of what most phonologists think of as phonology ... If these sorts of cases are shown to involve gradience, this would strike at the core of our understanding of the phonology, since these are the least disputable candidates for 'being phonology.'

In this paper I demonstrate that morphophonological patterns may be gradient, drawing on data from Uyghur backness harmony. I show that the Uyghur vowel space is asymmetrically fronted in non-initial

\footnotetext{
* I would like to thank the Uyghurs who let me stay in their village, shared their language with me, and even braved an earthquake with me. This paper has been greatly improved by discussions with Sharon Rose, Eric Baković, Marc Garellek, Rachel Walker, and Sarah Creel, as well as interactions with the audiences at UCSD's PhonCo and AMP.
} 
syllables in a manner not derivable from known phonetic forces of reduction or interpolation. I draw on independent evidence from elsewhere in the phonology of Uyghur to support the proposed phonological status of gradient harmony, and contend more generally that phonology is not ontologically categorical, but may exhibit both categoricality and gradience, as seen in Uyghur.

The paper is organized as follows. In $\S 2$, I detail the methods for data collection and analysis. In $\S 3$, I report results from the acoustic study and evidence in favor of a phonological analysis of gradience. Finally, in $\S 4$, I briefly discuss some of the implications of phonological gradience.

\section{Methods}

2.1 Procedures Each session was divided into training and recording phases. During the training phase, participants were exposed to a set of images corresponding to mono- and disyllabic nouns in their language. Some of these target lexical items are presented below in (1). In addition to this set of lexical items, participants learned a small set of pictorial-grammatical correspondences. For instance, they learned that any downward red arrow indicates the locative case, two outward facing red arrows indicate ablative case, and so on. After participants completed the training phase, the recording phase began. During this phase, participants were presented combinations of the lexical items and grammatical categories from training. As an example, when a picture of a jar of honey was paired with a downward red arrow, the speaker produced the word, [bal-da] 'honey-LOC,' and when a picture of a lake was paired with two outward facing red arrows, the speaker produced [køl-dyn] 'lake-ABL.' When speakers were unable to guess the target word from the prompt, they were given either the equivalent Russian word or a paraphrase in the target language. Sessions were conducted in a quiet room. Participants wore a Shure-SM10A unidirectional head-mounted microphone, and all data were recorded to a Marantz PMD 661 MKII digital recorder at a sampling rate of $44.1 \mathrm{kHz}$. Each session lasted between 45 and 90 minutes.

2.2 Stimuli Participants were presented a controlled set of target words containing all vowel contrasts in their language. Target words were derived from monosyllabic and disyllabic roots. Some example stimuli are shown below in (1). Monosyllabic roots ended either in a sibilant or a liquid (e.g. 1a,b), and disyllabic roots contained two vowels that agreed for the feature [high] (e.g. 1i-l).

\begin{tabular}{|c|c|c|c|}
\hline a. ba $\int$ & 'head' & g. $\mathrm{k} ø \mathrm{l}$ & 'lake' \\
\hline bal & 'honey' & h. gyl & 'flower' \\
\hline jol & 'road' & palta & 'axe’' \\
\hline 3wl & 'year' & zorma & 'persimmon' \\
\hline qul & 'slave' & qurum & 'soot' \\
\hline bæl & 'waist' & 1. jyzym & 'grape' \\
\hline
\end{tabular}

Roots were elicited in four cases, singular and plural numbers, and in first- and third-person possessive forms. The cases elicited were nominative, accusative, locative, and ablative. Example inflected forms from the roots /bal/ 'honey', /bæl/ 'waist', /jol/ 'road', and /køl/ 'lake' are shown below in (2). The forms in (2) preview the general harmony pattern found during fieldwork. Backness harmony targets all non-initial vowels, triggering the following three alternations, $\mathrm{a} \sim \mathfrak{x}, \mathrm{u} \sim \mathrm{i}, \mathrm{u} \sim \mathrm{y}$. The low vowel alternation is evident in the locative and plural suffixes $(2 \mathrm{c}, \mathrm{e})$, while the two high-vowel alternations are seen in the ablative and first-person possessive suffixes $(2 \mathrm{~d}, \mathrm{~g})$. High vowel alternations are additionally driven by rounding harmony, producing the four-way alternations observed in the ablative and first-person possessive suffixes. It is also important to note that word-final high vowels were immune to both backness and rounding harmony, always surfacing as [i] during data collection $(2 \mathrm{~b}, \mathrm{~h})$. I will return to this point later in the paper. 


\begin{tabular}{|c|c|c|c|c|}
\hline \multicolumn{5}{|c|}{ Example elicited forms } \\
\hline & /bal/ & /bæl/ & /jol/ & /køl/ \\
\hline a. NOM & bal & bæl & jol & køl \\
\hline b. $\mathrm{ACC}$ & bal-ni & bæl-ni & jol-ni & køl-ni \\
\hline c. LOC & bal-da & bæl-dæ & jol-da & køl-dæ \\
\hline d. $\quad A B L$ & bal-dun & bæl-din & jol-dun & køl-dyn \\
\hline e. $\mathrm{PL}$ & bal-lar & bæl-lær & jol-lar & køl-lær \\
\hline f. PL-LOC & bal-lar-da & bæl-lær-dæ & jol-lar-da & køl-lær-dæ \\
\hline g. PS.1S & bal-um & bæl-im & jol-um & køl-ym \\
\hline h. PS.3S & bal-i & bæl-i & jol-i & køl-i \\
\hline
\end{tabular}

In addition to these three alternations, two additional alternations arise due to vowel raising in the language. Low vowels in medial open syllables are raised and reduce, sometimes to the point of deletion (Lindblad 1990; Hahn 1991; Vaux 2001; Yakup 2005). In previous work, raising is formalized as adoption of a [+high] feature. However, raised vowels exhibited impressionistic differences from underlying high vowels in both quality and duration. As a result, raised vowels are treated as separate alternations throughout the paper, and are transcribed with a subscript to differentiate them from underlying high vowels. Two raised vowel alternations occur because raised vowels may undergo both backness and rounding harmony, which are exemplified with the roots, /palta/ 'axe', /sællæ/ 'turban', /xorma/ 'persimmon', and /tøpæ/ 'hill' in (3). In $(3 a, b)$, the structural description for raising is not met, and the underlying low vowels are output without change. In (3c) though, the root-final vowel occurs in a medial open syllable and undergoes raising. In (3d), two vowels undergo raising, the root-final low vowel and the vowel of the plural suffix.

\begin{tabular}{|c|c|c|c|c|}
\hline & & & & \\
\hline & /palta/ & /sællæ/ & /xorma/ & /tøpæ/ \\
\hline $\begin{array}{l}\text { NUM } \\
\text { PS 1S }\end{array}$ & palta & sællæ & xorma & tøpæ \\
\hline PS.IS & palta-m & sællæ-m & xorma-m & tøpæ-m \\
\hline PL & paltum & sælli $\mathrm{R}_{\mathrm{R}}-\mathrm{lær}$ & xormu $_{R}$-lar & tøpy $\mathrm{R}_{\mathrm{R}}-1 æ r$ \\
\hline PL-PS.3-LOC & paltu $\omega_{R}-l w_{R} r-u-d a$ & 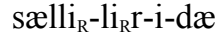 & xormu $_{R}-1 u_{R} r-u-d a$ & tøpy ${ }_{R}-1 y_{R} r-y-d æ$ \\
\hline
\end{tabular}

Words derived from monosyllabic roots were maximally three syllables in length, while words derived from disyllabic roots were maximally five syllables in length.

2.3 Participants Participants were recruited through existing relational networks in Chonja, Kazakhstan. Nine speakers (five females, mean age: 44.4 years, range: 19-63 years) participated in the study. All participants reported native fluency in the target language. Most participants also reported fluency in Kazakh and Russian.

2.4 Segmentation All sound files were segmented in Praat (Boersma and Weenink 2015) . The beginning and end of each vowel was set to the onset and offset of the second formant. In cases where the second formant persisted across flanking consonants, abrupt changes in the amount and distribution of energy in the spectrogram were used to indicate vowel onset and offset.

2.5 Statistical analysis After segmentation, the first three formants (F1-F3), and duration were measured at three points, $25 \%, 50 \%$, and $75 \%$ of vowel duration. To facilitate across-speaker comparisons, the data were z-score normalized (Lobanov 1971). Vowels that only occurred in initial syllables, specifically /o ø/, were excluded from the analysis since the study is examining positional variation in vowel quality. 6,836 vowel tokens were measured. Since word-final high vowels were invariant, they were also removed from the data set, leaving 5,927 vowels for the analysis.

The data were analyzed in R (R Core Team 2017), using the lme4 package (Bates et al. 2015). A mixed-effects linear regression was used to predict normalized F2 based on the following fixed effects: initial vowel backness, target vowel height, syllable number (counting from the left), root type (mono- or disyllabic), preceding consonant place of articulation, and following consonant place of articulation. The model incorporated two-way interactions between: preceding consonant place of articulation and target 
vowel height, following consonant place of articulation and target vowel height, initial vowel backness and target vowel height, initial vowel backness and syllable number, initial vowel backness and root type, and syllable number and root type. The model also incorporated the three-way interaction between initial vowel backness, syllable number, and root type. The model included two random intercepts, one for speaker and one for target vowel, as well as by-speaker and by-target vowel random slopes for syllable number. Likelihood ratio tests were used to assess statistical significance.

The key predictors to observe are the main effect of syllable number and the interaction between initial vowel backness and syllable number. Positional shifts for front vowels are observable from the main effect alone, whereas shifts for back vowels require examining both the main effect and interaction term.

2.6 Predictions Little work has been done on the positional realization of harmonic vowels, but Zsiga (1997:234-235) predicts that alternating vowels should be acoustically indistinguishable from nonalternating vowels. If the targets of harmony, i.e. non-initial syllables, are acoustically indistinguishable from initial-syllable trigger vowels, we can conclude that harmony operates categorically in the language, as is found for Turkish (Lanfranca 2012). Alternatively, it is possible that both classes of [back] vowels exhibit symmetric shifts toward a more central F2 in non-initial positions. This type of centralization is found in many languages (Johnson \& Martin 2001; Vayra \& Fowler 1992), and is attested in the related language, Kyrgyz (McCollum 2019). Lastly, it is possible that only one class of [back] vowels exhibits a positional shift in F2. This type of asymmetric shift is attested in related Kazakh (McCollum 2015; McCollum \& Chen 2019). Each of these three possible patterns and their possible analyses are schematized in Table 1.

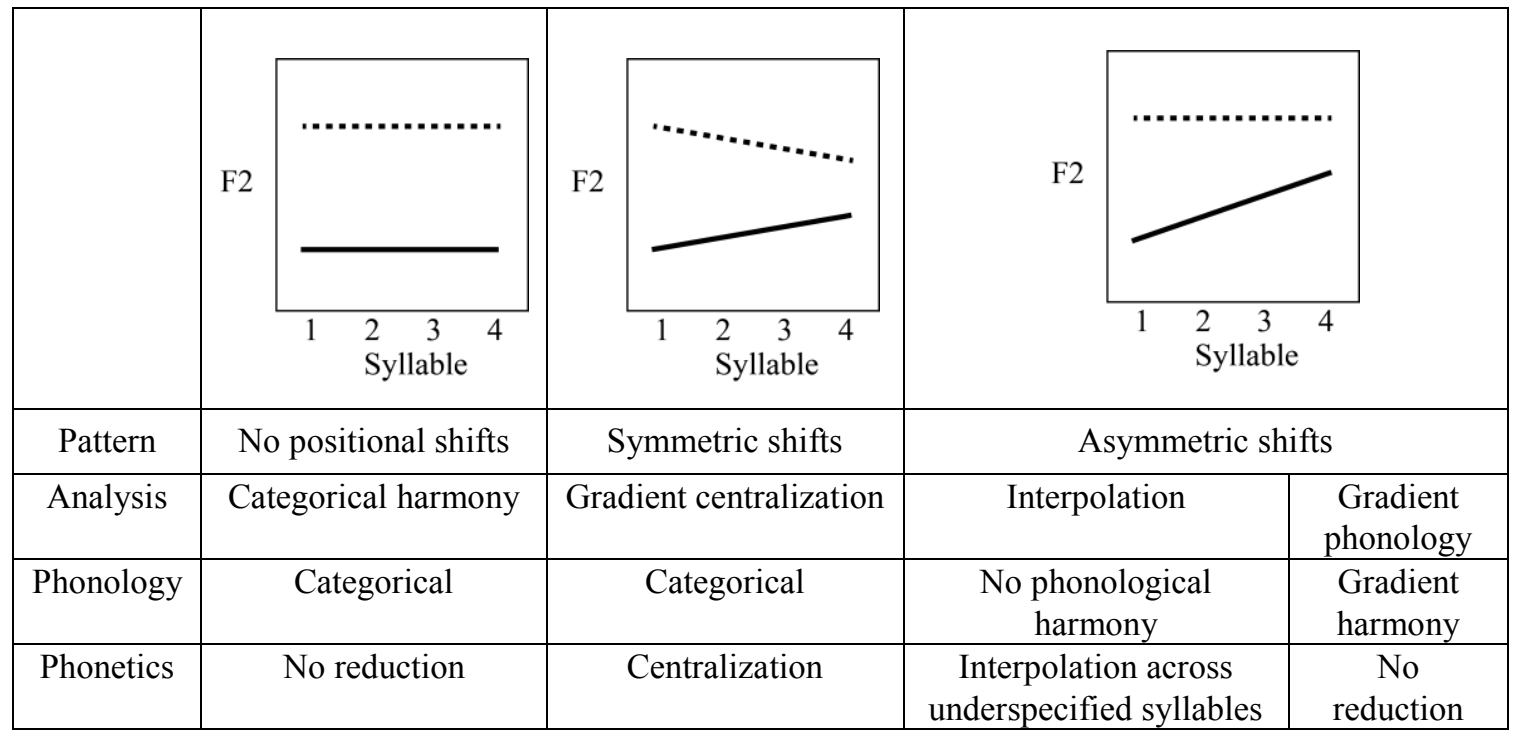

Table 1: Schema for possible patterns and their analysis. Each pattern is paired with at least one analysis, which involves a phonological and phonetic component.

Of the three possible patterns, analyzing the first two is straightforward- if no positional shifts occur throughout the word, then we can conclude that Zsiga's prediction is borne out. In this scenario, harmony operates categorically, also blocking phonetic reduction (Pearce 2008). If non-initial vowels undergo relatively symmetric shifts toward a central F2, such a pattern is analyzable as categorical phonology with gradient phonetic implementation in the form of centralization. Two possible analyses for the third, asymmetric pattern, are sketched out below.

One account of asymmetric positional shifts involves interpolation (see Cohn 1993 for an analysis). Under this analysis, the initial-syllable vowel is specified for [back]. In addition to the initial syllable, the right edge of the word is given a featural specification to reflect a default articulatory setting reached at the end of the larger prosodic unit (Gick et al. 2004; Wilson \& Gick 2006). Also studies on languages with 
vowel harmony have shown that default articulatory settings typically correspond to the unmarked feature value in the language (Hudu 2010; Allen et al. 2013). The recording setting used makes this analysis plausible; since words were recorded in isolation, each word also forms an entire utterance. This analysis hinges on all non-initial vowels being unspecified for [back] during the phonology, with speakers gradiently transitioning from the backness specification of the initial-syllable to the default articulatory setting at the end of the word. In essence, harmony is not phonological, but a rule of phonetic implementation ( Keating 1988, 1990; Cohn 1993).

Alternatively, one could develop an analysis of asymmetric gradience that falls out from phonological rather than phonetic factors. Under this analysis, [back] spreading subphonemically peters out over the course of the word, leaving each subsequent vowel slightly less assimilated to the active feature value. This analysis is consistent with a number of impressionistic descriptions, like Stegen (2002:137), which reports that ATR harmony in Rangi "seems to be gradient, i.e. having diminished effect with increase distance from the [+ATR] spreading vowel" (see Kirchner 1998:320-321; Casali 2002:25 for other similar descriptions).

\section{Results and analysis}

3.1 Results In Uyghur, syllable number does not exert a significant effect on F2 of front vowels [Syllable: $\beta=0.01, \chi^{2}(1)=0.02, p=.88$ ]. However, back vowels are produced with significantly increasing F2 by position [Backness : Syllable: $\left.\beta=0.35, \chi^{2}(1)=32.48, p<.001\right]$. In other words, the Uyghur vowel space undergoes an asymmetric fronting by position- back vowels are fronted in non-initial syllables while front vowels exhibit no concomitant changes by position. The asymmetry of these shifts is evident in Figures 1 and 2, and Tables 2 and 3. In Figures 1 and 2, observe that F2 of front vowels does not systematically vary by position. In contrast, F2 of the back vowels increases significantly and very systematically in non-initial syllables. In Figure 1, vowel shifts are shown by harmonic pairing, and in Figure 2 all positional shifts are shown within the vowel space.

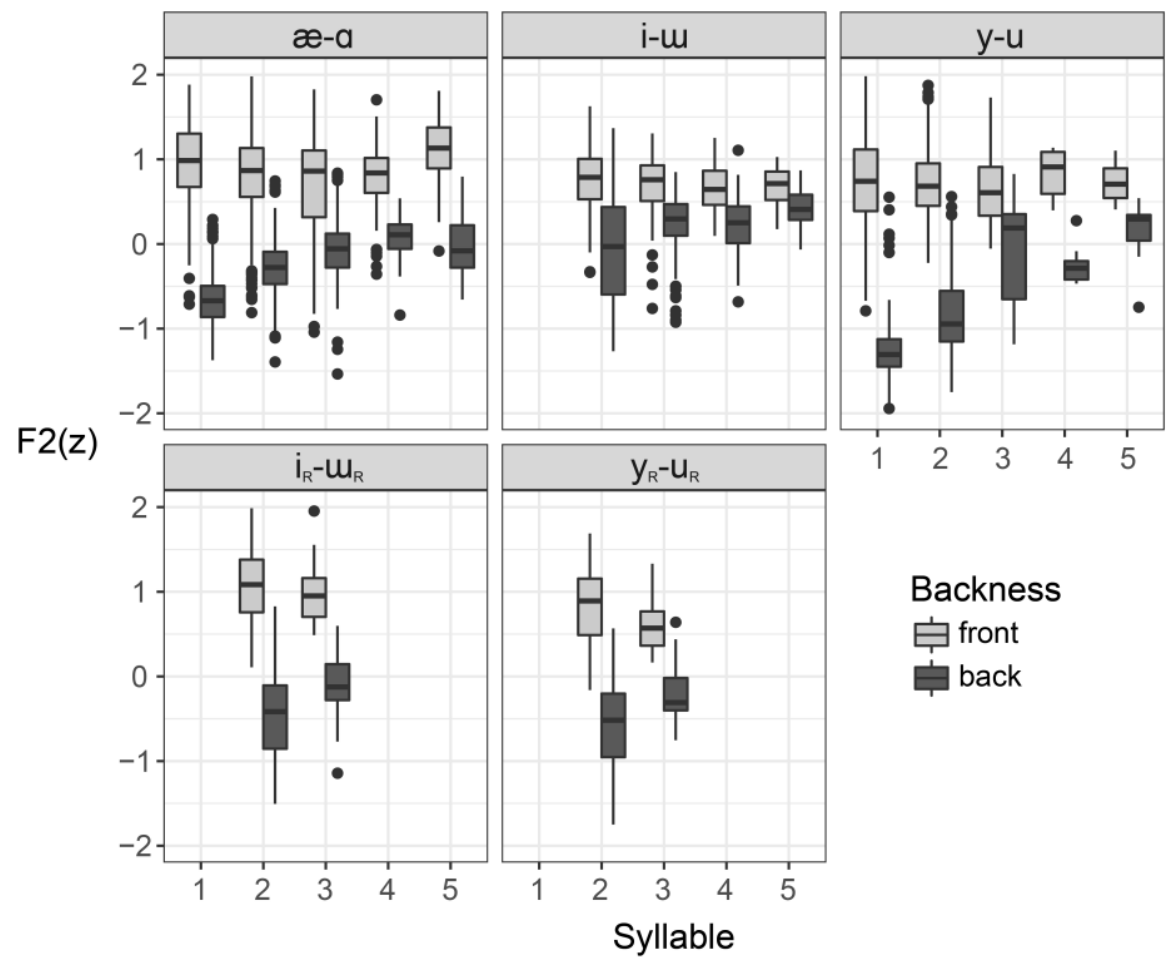

Figure 1: F2 (z) by position and harmonic pairing. Raised vowels are indicated by a subscript. 


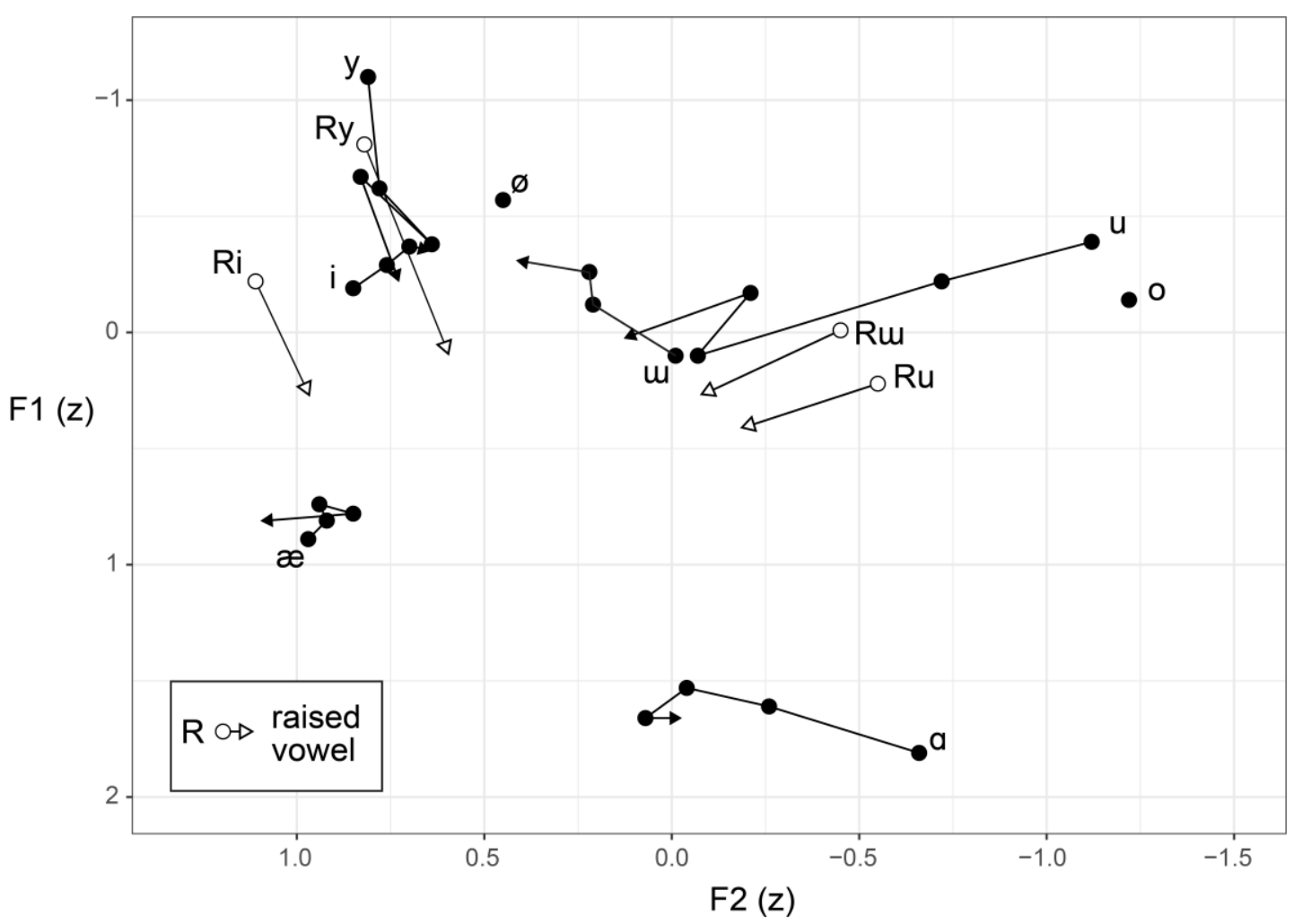

Figure 2: Mean vowel F1-F2(z) by position. Transcription-adjacent points indicate first-syllable means; arrows indicate vowel qualities in fifth syllables

\begin{tabular}{|c|c|c|c|c|c|c|c|c|c|}
\hline & \multicolumn{3}{|c|}{ Syllable 1} & \multicolumn{3}{|c|}{ Syllable 2} & \multicolumn{3}{|c|}{ Syllable 3} \\
\hline & F1 & F2 & $\mathrm{n}$ & F1 & $\mathrm{F} 2$ & $\mathrm{n}$ & F1 & $\mathrm{F} 2$ & $\mathrm{n}$ \\
\hline $\mathrm{a}$ & $1.81(0.53)$ & $-0.66(0.28)$ & 592 & $1.61(0.53)$ & $-0.26(0.32)$ & 523 & $1.53(0.55)$ & $-0.04(0.34)$ & 469 \\
\hline $\mathrm{o}$ & $-0.14(0.42)$ & $-1.22(0.24)$ & 207 & & & & & & \\
\hline $\mathrm{uI}$ & & & & $0.10(0.65)$ & $-0.01(0.60)$ & 114 & $-0.12(0.61)$ & $0.21(0.42)$ & 130 \\
\hline $\mathrm{u}$ & $-0.39(0.71)$ & $-1.12(0.84)$ & 290 & $-0.22(0.81)$ & $-0.72(0.71)$ & 135 & $0.10(0.48)$ & $-0.07(0.61)$ & 21 \\
\hline $\mathfrak{x}$ & $0.89(0.76)$ & $0.97(0.71)$ & 311 & $0.74(0.49)$ & $0.94(0.59)$ & 465 & $0.81(0.48)$ & $0.92(0.48)$ & 310 \\
\hline$\varnothing$ & $-0.57(0.26)$ & $0.45(0.29)$ & 252 & & & & & & \\
\hline i & & & & $-0.19(1.13)$ & $0.85(0.52)$ & 123 & $-0.29(0.46)$ & $0.76(0.25)$ & 92 \\
\hline $\mathrm{y}$ & $-1.10(0.82)$ & $0.81(0.62)$ & 328 & $-0.62(1.09)$ & $0.78(0.55)$ & 256 & $-0.38(0.41)$ & $0.64(0.38)$ & 55 \\
\hline $\mathrm{U}_{\mathrm{R}}$ & & & & $-0.01(0.59)$ & $-0.45(0.51)$ & 290 & $0.27(0.36)$ & $-0.08(0.32)$ & 113 \\
\hline $\mathrm{u}_{\mathrm{R}}$ & & & & $0.22(0.61)$ & $-0.55(0.53)$ & 123 & $0.41(0.48)$ & $-0.19(0.31)$ & 35 \\
\hline$i_{R}$ & & & & $-0.22(0.59)$ & $1.11(0.42)$ & 81 & $0.26(0.38)$ & $0.97(0.30)$ & 45 \\
\hline$y_{R}$ & & & & $-0.81(0.59)$ & $0.82(0.50)$ & 105 & $0.07(0.42)$ & $0.60(0.29)$ & 25 \\
\hline
\end{tabular}

Table 2: Mean F1-F2 (z, with SD) for vowels in syllables 1-3 


\begin{tabular}{|l|c|c|c|c|c|c|}
\hline & \multicolumn{3}{|c|}{ Syllable 4 } & \multicolumn{3}{c|}{ Syllable 5 } \\
\cline { 2 - 7 } & $\mathrm{F} 1$ & $\mathrm{~F} 2$ & $\mathrm{n}$ & $\mathrm{F} 1$ & $\mathrm{~F} 2$ & $\mathrm{n}$ \\
\hline $\mathrm{a}$ & $1.66(0.45)$ & $0.07(0.33)$ & 71 & $1.66(0.41)$ & -0.02 & 59 \\
\hline $\mathrm{u}$ & $-0.26(0.32)$ & $0.22(0.33)$ & 85 & $-0.31(0.38)$ & $0.41(0.24)$ & 28 \\
\hline $\mathrm{u}$ & $-0.17(0.42)$ & $-0.21(0.29)$ & 12 & $0.02(0.27)$ & $0.12(0.44)$ & 7 \\
\hline $\mathfrak{x}$ & $0.78(0.43)$ & $0.85(0.37)$ & 65 & $0.81(0.32)$ & $1.08(0.43)$ & 36 \\
\hline $\mathrm{i}$ & $-0.37(0.36)$ & $0.70(0.26)$ & 52 & $-0.36(0.38)$ & $0.66(0.30)$ & 12 \\
\hline $\mathrm{y}$ & $-0.67(0.26)$ & $0.83(0.31)$ & 6 & $-0.23(0.22)$ & $0.73(0.30)$ & 4 \\
\hline
\end{tabular}

Table 3: Mean F1-F2 (z, with SD) for vowels in syllables 4-5 (neither /o ø/ nor the raised vowels occurred in fourth or fifth syllables)

Given the asymmetric nature of the positional changes in F2 reported here, it is clear that harmony is not categorical, nor are the shifts due to symmetric centralization. Instead, results are more consistent with the phonetic interpolation and gradient harmony analyses. These two analyses differ crucially in two regards. First, the interpolation account demands that non-initial vowels be unspecified for [back] throughout the phonology, while the gradient phonology account predicts that non-initial vowels receive their specification during phonological computation. Second, the interpolation analysis predicts that all vowels should shift toward a relatively fixed value for F2, while the gradient phonology account makes no such prediction. Both analyses can account for the back vowels shifting forward in the vowel space, as seen above, but their predictions are distinct for the front vowels. The interpolation account predicts that all vowels, including the front vowels, should shift toward a single value for F2 while the gradient phonology analysis predicts that front vowels should not shift toward any discernible value for F2. In this way the interpolation account is constrained by phonetic economy, with all vowels shifting toward an F2 value that corresponds to a language-specific default articulatory setting. In contrast, the gradient phonology account predicts that [-back] is unmarked, and thus from a phonological point of view, no shifts are necessary or expected for any of the front vowels. In the next subsection I discuss independent evidence from consonant alternations and non-alternating high vowels that supports the gradient phonology account.

3.2 Evidence for gradient phonology If gradient fronting of back vowels is phonetic interpolation, then non-initial syllables should not receive a backness specification in the phonology, and as a result, [back] should not trigger phonological alternations in non-initial syllables. This prediction is incorrect, as is evident in dorsal consonant alternations in the language. Uyghur possesses five dorsal obstruent phonemes, $/ \mathrm{k} \mathrm{g} \mathrm{q} \mathrm{q} \chi /$. Leaving aside $/ \chi /$, which does not undergo any relevant alternations, the remaining four are contrastive in word-initial position $(4 \mathrm{a}-\mathrm{h})$, but alternate based on the backness of the adjacent vowel in noninitial positions (4i-p).

(4) Dorsal consonant alternations word-initial position (Schwarz 1992)
a. kæz 'tour (imperative)'
b. gæz 'yardstick'
c. kazzap 'swindler'
d. gas 'deaf'
e. qæst 'plot'
f. вæzæp 'anger'
g. qaz 'dig (imperative)'
h. ваz 'goose'

\begin{tabular}{|c|c|}
\hline \multicolumn{2}{|c|}{ non-initial syllables } \\
\hline i. $\quad$ æs-kæ & 'memory-DAT' \\
\hline gæz-gæ & 'yardstick-DAT' \\
\hline bæl-gæ & 'lower back-DAT’ \\
\hline$b a \int-q a$ & ‘head-DAT’ \\
\hline т. ваz-ва & 'goose-DAT’' \\
\hline bal-вa & ‘honey-DAT’ \\
\hline bæl-lær-gæ & 'lower back-PL-DAT' \\
\hline bal-lar-ва & 'honey-PL-DAT’ \\
\hline
\end{tabular}

The alternation between $/ \mathrm{g} / \mathrm{and} / \mathrm{b} /$ in non-initial syllables is the most informative, since these two segments differ in both place and manner of articulation. This difference in manner of articulation is key. There is no relationship between tongue body backness and constriction degree that would predict phonetic backing of the tongue to also reduce constriction degree, resulting in a fricative. Thus, the differential realization of the initial segment of the dative suffix in (4i-p) cannot be attributed to phonetic coarticulation 
from a flanking vowel, since at most, we would expect slight differences in tongue body backness, and not degree of constriction. In Lexical Phonological terms, this alternation is structure-preserving, being constrained by the structure of the Uyghur inventory, one hallmark of phonological alternations. In sum, Uyghur spreads phonological backness to non-initial syllables, which in turn triggers dorsal consonant alternations, e.g. $/ \mathrm{g} / \sim / \mathrm{r} /$.

The second piece of evidence that points to the phonological status of backness harmony in Uyghur is the realization of word-final high vowels. Recall from $(2 b, h)$ that these vowels do not alternate for backness or rounding harmony, instead surfacing as [i]. If the realization of non-initial vowels is due to interpolation toward a default articulatory setting at the end of the word, then these vowels should surface in tight conformity to the F2 target marking that default articulatory setting. If we look at Figure 2, there is enough positional change that might lead us to believe that shifts in non-initial vowel quality target an F2 value of about $0.5 \mathrm{z}$, somewhere between $/ \mathrm{i} /$ and $/ \mathrm{w} /$. If so, the interpolation account predicts that word-final high vowels should be realized with a similar F2, but they are not. Instead, word-final high vowels are always produced with a high F2 that far exceeds the F2 of alternating /i/ elsewhere in the language. Consider the realization of the ablative, third-person possessive, and accusative suffixes, shown in Figure 3. The vowel in the ablative suffix /-din/ is never word-final, and alternates based on the root vowel. The high vowel in the third-person possessive suffix /-i/ may occur word-medially, as in (3d), but may also occur wordfinally, as in (2h). Below we see that when this suffix occurs word-medially it alternates for harmony, but when it occurs word-finally it is always realized as a very peripheral front vowel. Lastly, the accusative suffix /-ni/ always occurred word-finally in the data collected, and in all cases surfaced as [i]. The average F2 for all word-final high vowels was $2.19 \mathrm{z}$. The vowel rendered as /i/ throughout could be transcribed more narrowly as [I] in most positions, but as a more peripheral allophone, [i], word-finally. This allophonic relationship between [i] and [I] is consistent with descriptions in Hahn (1986, 1991). Before moving on, it is important to note that, in contrast to the gradience seen for backness harmony, the neutralization of [back] and [round] among word-final high vowels appears quite categorical.

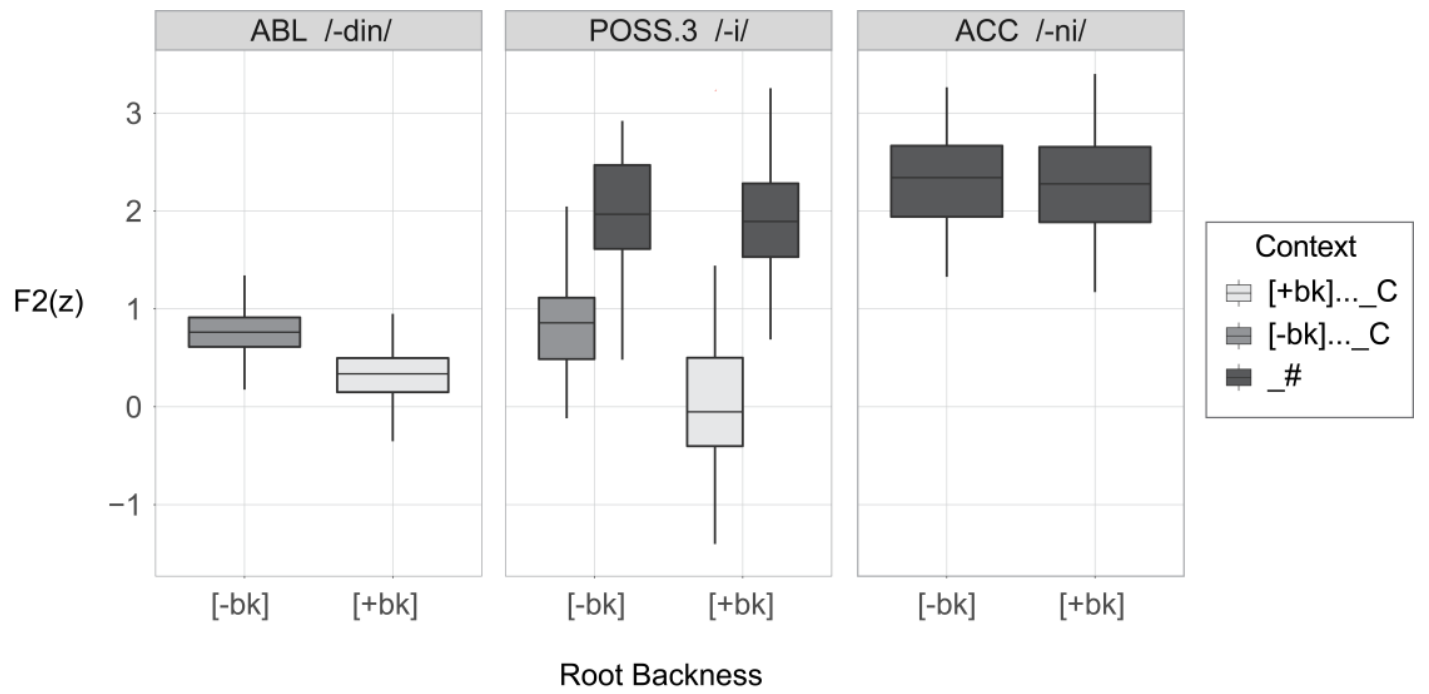

Figure 3: F2 (z) of ablative, third-person possessive, and accusative suffixes by root backness and position within the word

According to the interpolation analysis, all vowels should shift toward a value for F2 approximating the default articulatory setting in the language. From the data in Figure 2 we conjectured that perhaps a value of $0.5 \mathrm{z}$ might be consistent with such an analysis. However, the extremely fronted realization of these word-final high vowels undermines the interpolation analysis. If interpolation drives non-initial vowel backness and a default articulatory setting exists somewhere near $0.5 \mathrm{z}$, why do these vowels surface with such a high F2? Under the interpolation analysis, the realization of non-initial vowels is constrained by economy, but word-final high vowel neutralization is not economical, since it produces vowels inconsistent 
with a plausible F2 value from Figure 2. On the other hand, if F2 of these word-final high vowels actually approximates the acoustic value associated with a default articulatory setting, why don't the front vowels shift toward this high value of F2 in non-initial syllables? If peripheral [i] were indicative of such an articulatory setting, then the lack of across-the-board fronting is unexpected, and once again, not consistent with an analysis constrained by economy. Neither analysis is consistent with the data; word-final high vowel neutralization combined with the dorsal consonant alternations just discussed lend strong support for the gradient phonology analysis.

I thus argue that backness harmony in Uyghur is gradient, with its assimilatory effect subphonemically petering out over the course of the word. Before discussing the implications of this finding, it is important to point out that my analysis depends on [+back] being the active feature value. This analysis is supported by several pieces of evidence. First, when the backness of word-final high vowels is neutralized, these vowels surface as [-back]. Whether one construes this as a markedness constraint against [+round] or [+back] high vowels in word-final position, or as a faithfulness constraint protecting these vowels from harmony, the net result is that [+back] is active and [-back] is unmarked. Further support for the markedness of [+back] comes from loanword adaptation. As described in Yakup (2005) and Abdurehim (2014), loans are either borrowed with their native values for back, or they are fronted (e.g Arabic /avval/ 'first', Standard dialect /awal/, Kashgar dialect /æwwæl/). In sum, word-final high vowel fronting and dialectical patterns of loanword adaptation further support the claim that [+back] is active in the language (cf. Vaux 2000).

Under my analysis, backness harmony in Uyghur is both phonological and gradient. The claim advanced here is that phonology may be gradient. I am not claiming that all phonology is gradient (cf. Silverman 2006:214). Instead, I suggest that phonology may exhibit both categoricality and gradience. Although backness harmony in Uyghur is gradient, word-final high vowel neutralization is quite categorical.

\section{Discussion}

I have argued that backness harmony in Uyghur is gradient, but one might contend that the results reported above derive, not from the systematic operation of the phonology, but from the experimental methods employed during data collection. One might claim that the pattern is really a result of collecting words in isolation. In fact, this is the very prediction made by the phonetic interpolation account. If noninitial backness is unspecified in the phonology, harmony should produce drastically different outputs depending on the backness of the following word. There are several reasons to conclude that the data are not artefactual. First, the same methods were used to collect data on Kyrgyz, and the Kyrgyz data, as described in McCollum (2019), support an analysis of categorical phonology followed by gradient phonetic reduction. Thus, the methodology used here does not always produce results consistent with gradient phonology. Second, the same general pattern of gradient fronting of back vowels is found in neighboring Kazakh (McCollum 2015; McCollum \& Chen 2019). Furthermore, the Kazakh results have persisted across three different phrasal contexts, which more firmly establishes that this result is not due to the particular protocol used in this study. In addition to the evidence from Turkic, a number of impressionistic descriptions of harmony elsewhere in the world suggest that gradience is not confined to this particular language family (Harrington 1974; Stegen 2002; Casali 2002; Seidel 2008). Recall Stegen's (2002: 137) description of ATR harmony in Rangi from earlier, "This process seems to be gradient, i.e. having diminished effect with increasing distance from the [+ATR] spreading vowel." Moreover, Harrington (1974:5) describes sibilant harmony in Ventureño Chumash similarly, "The intent is perfect assimilation. But in actual practice the raising or lowering is largely only partial and frequently does not occur at all. Intermediate sounds between [s] and [J] ... arise by such imperfect assimilation." I predict that the methods employed in this paper, if applied to other languages, are likely to reveal gradient patterns in other languages, too.

If harmony may be gradient, then, in line with Cohn (2006), we should revisit our representational assumptions regarding phonology. One possible revision is to claim that all phonology is gradient, as argued in Pierrehumbert et al. (2000), Tucker \& Warner (2010), and Silverman (2006), among others. Essentially, these works contend that phonology and phonetics are not entirely distinct, but exist on a continuum, ranging from coarse, more categorical patterns to fine-grained, low-level phonetic detail. One 
shortcoming, as far I can see, of this approach is the distribution of sound patterns it predicts. If sound patterns exist on a continuum, one might predict a unimodal distribution across that continuum. Do we have evidence for such a distribution? Not as far as I know. Further, if we find that most patterns are bimodally distributed along this continuum, this would support a fundamental distinction between phonology and phonetics, consistent with the modular view. Our knowledge is too limited at present to argue convincingly for either a modular and unified view of human sounds, and I hope that these issues will lead to new research investigating the distribution of gradient patterns to better distinguish between these two views.

Finally, if gradience is an irreducible part of phonological computation, this suggests that phonological theory should incorporate continuously valued variables into its formalisms. Lionnet (2017) develops a similar line of reasoning, arguing that low-level phonetic effects are accessible to phonology in the form of subfeatural representations. These phonetic effects are then used by phonology to define a natural class for doubly-triggered rounding harmony in Laal. Lionnet's work differs from the present in two key respects: the source of gradience and the outputs of phonology. In Lionnet (2017) gradience originates in phonetics, and is accessed by phonology. In this paper, I contend that gradience may originate in phonology. Second, the outputs of phonology in Lionnet $(2017)$ are categorical, whereas they are clearly gradient here (cf. Flemming 2001; Flemming \& Cho 2017; Braver 2013, 2019).

If gradience is incorporated into phonological computation, this in turn supports this plausibility of formalisms more amenable to continuous variables, like Harmonic Grammar (Legendre, Miyata, \& Smolensky 1990) and Gradient Symbolic Computation (Smolensky \& Legendre 2006; Smolensky, Goldrick, \& Mathis 2014; Smolensky \& Goldrick 2016). For current discussion on the potential compatibility between gradient representational networks and linguistic theory, see (Pater 2019) and responses, (Berent and Marcus 2019; Dunbar 2019; Linzen 2019; Pearl 2019; Potts 2019; Rawski and Heinz 2019). Finally, if phonology may be gradient, this should motivate new work exploring the typology of gradient patterns, their learnability, and the connection between phonological gradience and other areas of human language.

\section{References}

Abdurehim, Esmael. 2014. The Lopnor dialect of Uyghur: A descriptive analysis. Publications of the Institute for Asian and African Studies 17. University of Helsinki.

Allen, Blake; Douglas Pulleyblank, and Oládiípọ Ajíbóyè. 2013. Articulatory mapping of Yoruba vowels: an ultrasound study. Phonology 30.2:183-210.

Bates, Douglas; Martin Machler; Ben Bolker, and Steve Walker. 2015. Fitting linear mixed-effects models using lme4. Journal of Statistical Software 67.1: 1-48.

Berent, Iris, and Gary Marcus. 2019. No integration without structured representations: Response to Pater. Language 95.1:e75-e86.

Bloomfield, Leonard. 1933. Language. Holt, Rinehart and Winston.

Boersma, Paul, and David Weenink. 2015. Praat: Doing phonetics by computer (version 5.4.18).

Braver, Aaron. 2013. Degrees of incompleteness in neutralization: Paradigm uniformity in a phonetics with weighted constraints. PhD thesis, Rutgers University.

Braver, Aaron. 2019. Modeling incomplete neutralization with weighted phonetic constraints. Phonology 36.1:1-36.

Casali, Roderic F. 2002. Nawuri ATR harmony in typological perspective. Journal of West African Languages 29.1: 343.

Chomsky, Noam, and Morris Halle. 1968. The sound pattern of English. Harper \& Row.

Cohn, Abigail C. 1993. Nasalisation in English: Phonology or phonetics. Phonology 10.1: 43-81.

Cohn, Abigail C. 2006. Is there gradient phonology? In Gradience in grammar: Generative Perspectives, Gilbert Fanselow, Caroline Féry, Matthias Schlesewsky, and Ralf Vogel, eds., 25-44. Oxford University Press.

Dunbar, Ewan. 2019. Generative grammar, neural networks, and the implementational mapping problem: Response to Pater. Language 95.1:e87-e98.

Ernestus, Mirjam. 2011. Gradience and categoricality in phonological theory. In The Blackwell Companion to Phonology, 2115-2136. Wiley-Blackwell.

Flemming, Edward. 2001. Scalar and categorical phenomena in a unified model of phonetics and phonology. Phonology 18.1: 7-44.

Flemming, Edward, and Hyesun Cho. 2017. The phonetic specification of contour tones: Evidence from the Mandarin rising tone. Phonology 34.1: 1-40. 
Gick, Bryan; Ian Wilson; Karsten Koch, and Clare Cook. 2004. Language-specific articulatory settings: Evidence from inter-utterance rest position. Phonetica 61.4: 220-33.

Hahn, Reinhard. 1986. Modern Uighur language research in China: Four recent contributions examined. Central Asiatic Journal 30.1/2: 35-54.

Hahn, Reinhard. 1991. Spoken Uyghur. University of Washington Press.

Harrington, John P. 1974. Sibilants in Ventureño. International Journal of American Linguistics 40.1: 1-9.

Hudu, Fusheini Angulu. 2010. Dagbani tongue-root harmony: A formal account with ultrasound investigation. PhD thesis, University of British Columbia.

Johnson, Keith, and Jack Martin. 2001. Acoustic vowel reduction in Creek: Effects of distinctive length and position in the word. Phonetica 58.1-2: 81-102.

Keating, Patricia A. 1985. The phonology-phonetics interface. UCLA Working Papers in Phonetics 62: 14-33.

Keating, Patricia A. 1988. Underspecification in phonetics. Phonology 5.2: 275-92.

Keating, Patricia A. 1990. The window model of coarticulation: Articulatory evidence. In Papers in Laboratory Phonology I: Between the Grammar and Physics of Speech, John Kingston and Mary E. Beckman, eds., 451-470. Cambridge University Press.

Kiparsky, Paul. 1985. Some consequences of Lexical Phonology. Phonology 2.1: 85-138.

Lanfranca, Mark. 2012. An acoustic study of underspecified vowels in Turkish. MA thesis, University of Kansas.

Legendre, Géraldine; Yoshiro Miyata, and Paul Smolensky. 1990. Harmonic Grammar: A formal multi-level connectionist theory of linguistic well-formedness: Theoretical foundations. Institute of Cognitive Science Technical Report 90-5. University of Colorado.

Linzen, Tal. 2019. What can linguistics and deep learning contribute to each other? Response to Pater. Language 95.1:e99-e108.

Lionnet, Florian. 2017. A theory of subfeatural representations: The case of rounding harmony in Laal. Phonology 34.3: 523-564.

Lobanov, Boris M. 1971. Classification of Russian vowels spoken by different speakers. Journal of the Acoustical Society of America 49.4B: 606-608.

McCollum, Adam G. 2015. Labial harmony in Kazakh: Descriptive and theoretical issues. MA thesis, University of Florida.

McCollum, Adam G. 2019. Positional effects on vowel quality in Kyrgyz. Unpublished. UC San Diego.

McCollum, Adam G., and Si Chen. 2019. Kazakh. Journal of the International Phonetic Association 49.

Mohanan, Karuvannur Puthanveettil. 1982. Lexical Phonology. PhD thesis, Massachusetts Institute of Technology.

Öhman, Sven E.G. 1966. Coarticulation in VCV utterances: Spectrographic measurements. Journal of the Acoustical Society of America 39.1: 151-68.

Pater, Joe. 2019. Generative Linguistics and neural networks at 60: Foundation, friction, and fusion. Language 95.1:e41-e74.

Pearce, Mary. 2008. Vowel harmony domains and vowel undershoot. In UCL Working Papers in Linguistics, 20:115140.

Pearl, Lisa S. 2019. Fusion is great, and interpretable fusion could be exciting for theory generation: Response to Pater. Language 95.1:e109-e114.

Pierrehumbert, Janet; Mary E Beckman, and D Robert Ladd. 2000. Conceptual foundations of phonology as a laboratory science. In Phonological Knowledge: Conceptual and Empirical Issues, Noel Burton-Roberts, Philip Carr, and Gerard Docherty, eds., 273-304.

Port, Robert, and Michael O'Dell. 1985. Neutralization of syllable-final voicing in German. Journal of Phonetics, 13.4: 455-471.

Potts, Christopher. 2019. A case for deep learning in semantics: Response to Pater. Language 95.1:e115-e124.

R Core Team. 2017. R: A language and environment for statistical computing (version 3.4.2). R Foundation for Statistical Computing.

Rawski, Jonathan, and Jeffrey Heinz. 2019. No free lunch in linguistics or machine learning: Response to Pater. Language 95.1:e125-e135.

Schwarz, Henry G. 1992. An Uyghur-English dictionary. East Asian Research Aids \& Translations, Vol. 3. Western Washington University.

Seidel, Frank. 2008. A grammar of Yeyi: A Bantu language of southern Africa. Vol. 33. Köppe.

Silverman, Daniel. 2006. A critical introduction to phonology: Of sound, mind, and body. Continuum Critical Introductions to Linguistics.

Smolensky, Paul, and Matthew Goldrick. 2016. Gradient symbolic representations in grammar: The case of French liaison. Unpublished. Johns Hopkins University and Northwestern University. 
Smolensky, Paul; Matthew Goldrick, and Donald Mathis. 2014. Optimization and quantization in gradient symbol systems: A framework for integrating the continuous and the discrete in cognition. Cognitive Science 38: 11021138.

Smolensky, Paul, and Géraldine Legendre, eds. 2006. The harmonic mind: From neural computation to OptimalityTheoretic grammar. Vol. 1-2. MIT Press.

Stegen, Oliver. 2002. Derivational processes in Rangi. Studies in African Linguistics 31.1/2: 129-154.

Tucker, Benjamin V, and Natasha Warner. 2010. What it means to be phonetic or phonological: The case of Romanian devoiced nasals. Phonology 27.2: 289-324.

Vaux, Bert. 2000. Disharmony and derived transparency in Uyghur vowel harmony. In Proceedings of the North East Linguistic Society, 30:672-698.

Vayra, Mario, and Carol A. Fowler. 1992. Declination of supralaryngeal gestures in spoken Italian. Phonetica 49.1: 48-60.

Warner, Natasha; Allard Jongman; Joan Sereno, and Rachèl Kemps. 2004. Incomplete neutralization and other subphonemic durational differences in production and perception: Evidence from Dutch. Journal of Phonetics 32.2: 251-276.

Wilson, Ian, and Bryan Gick. 2006. Articulatory settings of French and English monolinguals and bilinguals. Journal of the Acoustical Society of America 120.5: 3295-3296.

Yakup, Abdurishid. 2005. The Turfan dialect of Uyghur. Turcologica 63. Harrassowitz Verlag.

Zsiga, Elizabeth. 1997. Features, gesture, and Igbo vowels. Language 73.2: 227-274. 